\title{
Exercise and heart disease: cardiac findings in fatal cycle accidents
}

Department of Histopathology, Northern General Hospital, Herries Road, Sheffield S5 7AU A Kennedy

Correspondence to: Dr Kennedy.

\author{
Alexander Kennedy
}

\begin{abstract}
Background-Regular cyclists have been found to have a lower incidence of coronary events (CHD) than the general public. Non-invasive studies have found that competitive cyclists develop a cardiac hypertrophy that is physiological and reversible.

Methods-To obtain pathological support for these observations, the postmortem findings of 32 cyclists killed in accidents have been compared with those in a control group of 32 other road traffic accidents, which were matched with the cyclists by sex, age, and year of death. Findings-Large myocardial scars and complete blockage of a coronary artery were only found in the controls; serious stenoses of coronary arteries $(>50 \%)$ were found in eight controls but in only one of the cyclists. Of the cyclists, 25 had normal coronary arteries as compared with 14 of the controls. The mean age of the cyclists with evidence of CHD was greater than that of similarly affected controls. The heart weights of the two groups were almost the same but heart weight varied with the degree of CHD. The heart weight of the healthy cyclists ( $389 \mathrm{~g})$ was greater than that of the healthy controls (371 g) but this was not statistically significant.

Interpretation-The results are in keeping with the concept that regular exercise provides some protection from the development of CHD and that cycling may be a valuable form of exercise in this respect. This may be of importance as the number of physically active occupations declines. (Br F Sports Med 1997;31:328-331)
\end{abstract}

Keywords: coronary heart disease; exercise; cyclists; cardiac hypertrophy

For over forty years, since the work of Morris, it has been known that there is an inverse relation between physical activity of work and the incidence of ischaemic heart disease (CHD).

These findings are supported by the work of Paffenbarger in the USA. ${ }^{2}$ Two separate studies have reported a reduced incidence of CHD in cyclists. ${ }^{34}$ Also there is evidence obtained by ultrasound that competitive cyclists ${ }^{5-8}$ develop a cardiac hypertrophy, which is reversible and which is partly seasonal, therefore it could be predicted that cyclists coming to necropsy after road traffic accidents might be expected to have less coronary artery disease and heavier hearts than the general population. This paper describe an attempt to explore these relations by a retrospective study of the postmortem reports of 32 pedal cyclists killed in accidents and comparing them with those relating to 32 other road traffic accidents matched by sex, age, and year of death.

\section{Methods}

A previous study of injuries sustained in fatal pedal cycle accidents ${ }^{9}$ had found 28 cases in Sheffield and Barnsley during the years 1979 to 1993 inclusive. Of these 14 cases were less than 18 years old and these have not been included in this study but the records from the east side of South Yorkshire, comprising Rotherham and Doncaster, were available for the years 1985 to 1994 and among these a further 18 adult cases were found. As in the previous study, for each case a control was chosen matched by sex, age and, as far as possible, year of death. The matches were made before any of the postmortem records were studied so that any form of bias was avoided.

The matching by sex was complete and where there was difficulty in finding a control of the same age a control of a slightly lesser age was chosen to avoid any bias introduced because of the rise in incidence of atheroma with age. The data recorded were age, sex, heart weight, condition of the coronary arteries, the presence of scars or fibrosis in the myocardium, and the condition of the aorta. Any additional information to CHD was also noted. To aid analysis of the data a semi-quantitative scale was used grading the evidence of ischaemic heart disease from $0-3$ where: 0 , normal coronary arteries and myocardium; 1 , coronary atheroma described as "mild" or $<50 \%$ stenosis; 2 , coronary atheroma with $>50 \%$ stenosis; 3 , atheroma with complete blockage of one or more coronary arteries and/or the presence of one or more myocardial scars.

The significance of the results was assessed using a commercial statistical software package (C-Stat, Cherwell Scientific). The study was conducted with the help and cooperation of the coroners for the West and East Divisions of South Yorkshire and the permission of the pathologists who had prepared the postmortem reports was obtained in each case.

\section{Results}

The mean age of the cyclists was 44 years (1887 , SD 17.2) and that of the controls was 43 (17-87, SD 17.3). All but one of the cases were male. Table 1 summarises the main cardiac findings. 
Table 1 Summary of the cardiovascular findings recorded in cyclists and in the controls

\begin{tabular}{lll}
\hline & Cyclists & Controls \\
\hline Heart weight (range (SD)) & $395 \mathrm{~g} \mathrm{(275-540(60.4))}$ & $406 \mathrm{~g}(250-610(85.4))$ \\
Normal heart and coronary arteries & 25 & 14 \\
Mild coronary atheroma (< 50\% stenosis) & 6 & 10 \\
Moderate atheroma (50\% stenosis or & 1 & 6 \\
greater) & 0 & 2 \\
Complete occlusion of a coronary artery & 0 & 3 \\
Myocardial scars & & \\
\hline
\end{tabular}

Table 2 Distribution of the grades of CHD between the cyclists and controls

\begin{tabular}{lrlll}
\hline Grade & 0 & 1 & 2 & 3 \\
Cyclists & 25 & 6 & 1 & 0 \\
Controls & 15 & 9 & 4 & 4 \\
\hline
\end{tabular}

The differences in the distributions of the lesions in the two groups are significant. $\chi^{2}=8.900, \mathrm{df}=3, \mathrm{p}=0.0307$.

The findings related to coronary artery disease may be summarised using, the grading system, in table 2 , which shows much less heart disease in the cases as compared with the age matched controls.

Although there was no significant difference in heart weight between the two groups it was found that heart weight was positively related to the degree of CHD (table 3) so that any physiological hypertrophy seen in the cyclists may be masked by pathological hypertrophy in the non-cyclists. The mean heart weights of all subjects in which there was no evidence of CHD were very similar; the mean heart weight of the cyclists in this group was $389 \mathrm{~g}$ as compared with $378 \mathrm{~g}$ in the controls but this was not significant.

The controls tended to have more aortic atheroma than the cyclists but these findings were entirely subjective and the different pathologists were inconstant in their methods of recording these data. The other interesting finding was that the cyclists with evidence of CHD tended to be older than the controls with a similar degree of disease (table 4).

\section{Discussion}

In this study cyclists killed in road traffic accidents were found to have less CHD than age matched controls and evidence of even moderate CHD was limited to the control group except for a single cyclist who was 78 at the time he was killed. The one female case had no evidence of either CHD or aortic atheroma but her control, who happened to be two years younger, was found to have $50 \%$ occlusion of the anterior descending branch of her left coronary artery. None of the cyclists had myocardial scars and, subjectively, the original pathologists reported less aortic atheroma.

Table 3 Relation between grade of CHD and heart weight in both cyclists and controls

\begin{tabular}{lllll}
\hline Grade of CHD & 0 & 1 & 2 & 3 \\
Heart weight (g) & 390 & 399 & 402 & 492 \\
\hline
\end{tabular}

Table 4 Mean ages of cyclists and controls with different grades of $\mathrm{CHD}$

\begin{tabular}{llll}
\hline & Grade 1 & Grade 2 & Grade 3 \\
Cyclists & 65 & 78 (one case) & $\frac{-}{61}$ \\
Controls & 50 & 49 & \\
\hline
\end{tabular}

These results, on a smaller scale, are in agreement with the results of the autopsy survey of Morris and Crawford, ${ }^{10}$ which showed that people in physically active occupations had less evidence of CHD at postmortem compared with those who had been sedentary. Although the numbers are small the present findings show a clear difference between the victims of cycle accidents and those of other road traffic accidents with regard to the presence of signs of CHD but the results need to be viewed from the point of view of the reliability of the data, overlap between the cyclists and the controls as well as the possible bias as a result of people with CHD having given up cycling - that is, the findings may be because of selection and not protection.

Medicolegal necropsy reports are often criticised as being drawn up in the absence of clinical data and the reports that were reviewed were compiled by a number of different pathologists. In this series half of the reports had been written either in the teaching hospitals or by members of the University Department of Forensic Pathology; while the standards were more mixed in those reports compiled in the non-teaching hospitals, many of these also were of good quality. With regard to the pathology of the heart, all the reports were adequate and they were probably better than the average coroner's postmortem report. Each pathologist would have known that all these cases would have gone to inquest at which many of the interested parties would have legal representation; cardiovascular factors are of considerable importance in road traffic accidents as they may make the distinction between natural and accidental death, which may have considerable financial importance. Unfortunately the body weights were seldom recorded as only a few mortuaries have the necessary facilities; this limits the value and significance of the recorded heart weights. The presence or absence of myocardial scars or complete blockage of a coronary artery may be regarded as reliable observations but there are problems in the assessment of lesser degrees of coronary atheroma. It is also relevant that the pathologists who wrote the reports could not have known that the reports would be analysed up to 15 years later. All these findings had been made with the naked eye and the descriptions varied from "mild" to an assessment of the area of lumen lost; all those assessed at greater than $50 \%$ were regarded as significant and placed in grade 2 and anything less was placed in grade 1. These assessments of stenosis probably overestimate the degree of obstruction for reasons explained by Mann and Davies. " If grades 0 and 1 are combined and compared with the sum of grades 2 and 3 , a $2 \times 2$ table may be constructed but the differences are still significant at the $2 \%$ level using Yates's correction.

Cyclists are not a separate section of the population and a person may be a motorist, a cyclist and a pedestrian at different times of the same day so that the time of accidental death could, theoretically, determine whether an individual was included among the cases or in the controls. This is unlikely to have been an 
important factor for two reasons. Firstly, South Yorkshire is a hilly area; Sheffield and Barnsley are very hilly and in such areas cycling can only be carried out on a regular basis as occasional cyclists find that they lack the fitness needed to climb the hills. It seems probable that all of the cases were regular cyclists. More convincingly, any overlap between the exercise patterns of the cases and the controls would reduce the differences between the two groups but the differences are statistically significant so that it may be concluded that any confusion of this sort, far from negating the findings, increases their significance.

The major factor in the deaths of all these cyclists was trauma and $73 \%$ died immediately or within hours of the accident; less than $10 \%$ survived for more than a week. As these deaths were accidental those investigating them had concentrated on the factors leading up to the accidents rather than on the level of training of the victims and records of their physical activity were only available in 13 cases. Two undertook regular long cycle tours and three were on training runs so it is probable that these people each covered at least 2000 miles per annum. Another seven used their machines for commuting or were described as "regular" cyclists but no further information was available. One cyclist probably took little exercise for he only took up cycling when he lost his driving licence because of an alcohol problem and he used an electrically assisted cycle; he was a man of 39 who had a heart of $400 \mathrm{~g}$ and, interestingly, he was one of those cyclists who did have some evidence of CHD in the form of "minimal" coronary atheroma. Another interesting finding concerns a man of 53 who was a regular cyclist and in whom the pathologist found no evidence of atheroma and commented that this was unusual as the man had been known to be a diabetic for many years. Nothing is known about the physical activity of members of the control group. It could be argued that the cyclists were an especially fit self selected group and that those who develop CHD give up cycling so that the findings are a result of selection rather than protection. To some extent this must happen but this is an objection to most investigations of this subject, which has been analysed by Paffenbarger et al ${ }^{12}$ who conclude that the protection hypothesis is still valid. The observation has been consistent, it is independent of other risk factors, exercise has been shown to reduce the risk of sudden death, and the effect has been seen in experimental studies. In this study it was found that the mean age of those cyclists with some degree of $\mathrm{CHD}$ was much older than those of the controls of the same grade (table 3 ). There were no cyclists in grade 3 and only one in grade 2; the numbers are very small but the differences are in keeping with the conclusion of Morris and Crawford that those who are physically active develop CHD at a later age than the sedentary. ${ }^{10}$

The finding that there was relatively little evidence of CHD in cyclists killed in accidents is in contrast with those of series of cases of unexpected sudden death during exercise, which have been published over the past 20 years. Most of these victims have been found to have heart disease, which has either been unsuspected during life or which the subjects have chosen to ignore. The publications have been mainly concerned with deaths associated with squash or running and all have shown a high incidence of CHD. The other, less frequent, causes of death include hypertrophic cardiomyopathy, unsuspected myocarditis, and non-cardiac conditions such as sub-arachnoid haemorrhage. The notable exception to this generalisation has been the Swedish orienteers who have suffered an epidemic of myocarditis. ${ }^{13}$ Lynch reported a series of sudden death unexpected deaths of British soldiers occurring within 24 hours of sport or other strenuous activities ${ }^{14} ; 63 \%$ of these were associated with CHD and in three men, aged 42,34 , and 36 , the precipitating activity was cycling. All three had severe disease of the proximal parts of their coronary arteries but there is no information about their states of fitness or their previous medical histories. Exercise increases heart rate, blood pressure, and blood flow so increasing both hydrostatic and shear stress on the arterial wall and increasing the danger of rupture of any existing atheromatous plaque. This may result in thrombosis, dissection or microembolism downstream in the myocardium. Therefore it is inevitable that in cases of sudden unexpected death during exercise a high incidence of CHD will be found but, in the present series in which death was traumatic, CHD was infrequent.

One of the major changes in lifestyle in this century has been a reduction in the physical activity of work and even some of the findings of Paffenbarger could only be repeated with difficulty as the work of stevedores has changed as the result of containerisation and the use of pallets and fork life trucks. It has been claimed that lack of physical activity is the biggest single risk factor for CHD in the United States. ${ }^{15}$ If humans in the modern world cannot exercise at work they must do it in leisure time or while travelling. In the survey of the effects of exercise during leisure time, it was found that in the $3.5 \%$ of men who reported vigorous cycling, the attack rate of CHD was much lower and that there was some reduction with lesser levels of cycling. ${ }^{4}$ In a longitudinal investigation of Dutch commuters it has been found that the cyclists were fitter as judged by maximal external power and maximal oxygen uptake. ${ }^{16}$ However there were no significant changes in total cholesterol concentrations, HDL cholesterol concentrations or in blood pressure but the investigation lasted only 12 months, the distances cycled were modest, and Holland is notably free of hills. In her introduction to this study Hendricksen states that a large part of the Dutch population age 16 years or older is active in sport and that $34 \%$ are inactive; this suggests that she was studying people who are much more active than the British. There was no investigation into haematological factors, which may be very important in the progression of atheroma some of which, 
such as fibrinogen, are improved by exercise. ${ }^{17}$ Apart from the environmental benefits of cycling, there may be good grounds for encouraging a modal shift to the bicycle both as a means of transport and as part of any CHD prevention programme. On the other hand, these findings were made in a hilly area where cycling entails considerable effort and the benefits might not be as dramatic in flatter parts of the country. More data are required about the cardiovascular pathology of those who exercise regularly.

I am greatly indebted to $\mathrm{Mr} \mathrm{C}$ Dorries and $\mathrm{Mr} \mathrm{S}$ Hooper for permission to gather these data and to their respective staffs fo their considerable assistance. The older records were studied in the Sheffield Archives with the help of Mrs M Turner. I wish to thank the pathologists of South Yorkshire who allowed me to use the data from their reports and Mrs L A Norcliffe for secretarial assistance.

1 Morris JN, Heady JA, Raffle PAB, et al. Coronary heart disease and physical activity of work. Lancet 1953;ii:10537,1111-20.

2 Paffenbarger RS, Hyde RT, Jung DL, Wing AL. Epidemiology of exercise and coronary heart disease. Clin Sports Med 1984;3:297-318.

3 Robertson HK. Heart disease in lifelong cyclists. BMf $1975 ; 2: 1635-6$.
4 Morris JN, Clayton DG, Everitt MG, et al. Exercise in leisure time: coronary attack and death rates. $\mathrm{Br} \mathrm{Heart} f$ 1990;63:325-34

5 Vollmer-Larsen A, Vollmer-Larsen B, Kelbaek H, Godtfredson J. The veteran athlete: an echocardiographic comparison of veteran cyclists, former cyclists and non-athletic son of veteran cyclists, former cyclists and subjects Acta Physiol Scand 1989;135:393-8.

6 Shapiro LM. Physiological left ventricular hypertrophy. $B$ Heart $\mathcal{F} 1984 ; 52: 130-5$

7 Fagard R, Aubert A, Staessen J, Eynde EV, Vanhees L Amery A. Cardiac structure and function in cyclists and runners: a comparative echocardiographic study. Br Heart $\mathcal{f}$ 1984; 52:124-9.

8 Bekaert I, Pannier JL, van de Weghe C, et al. Non-invasive evaluation of cardiac function in professional cyclists. $B$ Heart $\mathcal{F} 1981 ; 45: 213-18$

9 Kennedy A. The pattern of injury in fatal pedal cycle accidents and the possible benefits of cycle helmets. $\mathrm{Br}$ Sports Med 1996;30:130-3.

10 Morris N, Crawford D. Coronary heart disease and physical activity of work: evidence of a national necropsy survey. BMF 1958;2:1485-96.

11 Mann JM, Davies MJ. Assessment of the severity coronary heart disease at postmortem examination. Are the measheart disease at postmortem examination. Are

12 Paffenbarger RS, Hale WE, Brand RJ, Hyde RT. Workenergy level, personal characteristics and fatal heart attack energy level, personal characteristics and fatal heart attack:

13 Wesslen L, Pahlson C, Lindquist $\mathrm{O}$, et al. An increase in sudden unexpected cardiac deaths among young Swedish orienteers during 1979-1992. Eur Heart f 1996;17:90210.

14 Lynch P. Soldiers, sport and sudden death. Lance 1980;i:1235-7.

5 Casperson CJ. Physical activity and coronary heart disease. Physician and Sports Medicine 1987;15:43-4.

16 Hendricksen IJM. The effect of commuter cycling on physical performance and on coronary heart disease risk factors. (Thesis). Amsterdam: University of Amsterdam, 1996.

17 Thompson WD, Smith EB. Atherosclerosis and the coagulation system. F Pathol 1989;159:97-106.

\section{Olympic freak show?}

Preparation of top level athletes entails intensive manipulation of their physiology and psychology. This is done mainly through controlling their lifestyle and diet, partly because of arbitrary limits set on the range of drugs that may be used to achieve the desired changes. I have argued ${ }^{1}$ that biotechnology, including genetic engineering, is opening new possibilities for producing athletic champions. Should we use these new means?

No, of course not, says the knee jerk reaction. I am not quite so sure. Sport, we are told, is a "good thing". Well, yes, people should take some exercise, and maybe it's even ok to encourage them to gang together in teams to slaughter rival teams. No doubt there was a time when sports champions were rounded people, mens sana in corpore sano, who trained a bit, ran their race, then got on with the other things in their lives. But not now. Becoming a top class athlete is a full time commitment and requires the services of dedicated teams of physiologists and psychologists. And if these turn out insufficient, maybe the pharmacologist can help. The combination of big money, national prestige, and prima donna status for the champion are irreversibly separating top level sport from any ideals. Each year the gap widens. Increasingly, world championships will be the province of one dimensional dehumanised products of a ruthless people engineering industry.
Professional telly sport has none of the virtues of participative amateur sport-it enriches a few, destroys a few, and turns millions into couch potatoes. We would be better off without it. But there is no hope of stopping its corrosive influence by laws or regulations. Only education can defeat it. As with antismoking campaigns, the aim must be to stop the practitioners being seen as role models. This is where cloning, genetic engineering, and the rest can help. Give the drug designers and genetic engineers free rein and they will turn professional sport into a freak show. Remember the East German athletes of the 1970 s - didn't they have a decidedly factory farmed look to them? Would you want your child to have been one of them? We can build on that first flicker of revulsion. The sacrifice of a few unfortunates-and it will be a few because of the cost-might be a modest price to pay for returning the rest of us to a state where sport is played by real people for fun.

ANDREW P READ

Professor of Human Genetics University of Manchester Department of Medical Genetics St Mary's Hospital Manchester M13 OfH

1 Read AP. Cloning for gold. Br $\mathcal{F}$ Sports Med 1997;31: 174. 